\title{
The paradox of planning for transformation: the case of the integrated sustainable urban development strategy in València (Spain)
}

\author{
Jordi Peris ${ }^{1 *}$ and Marga Bosch ${ }^{2}$
}

\footnotetext{
* Correspondence: jperisb@dpi.upv. es

'Universitat Politècnica de València, València, Spain

Full list of author information is available at the end of the article
}

\begin{abstract}
Urban transformation towards sustainability requires deep systemic change in economic, social, environmental, cultural, organisational, governmental, and physical terms. Considering this challenge, this paper aims to explore the potentials and limitations of urban planning to incorporate an urban transition management approach that strives to enable such deep transformation processes.

Taking the Integrated Sustainable Urban Development (ISUD) Strategy for district regeneration in Valencia (Spain) as a case study, the analysis and discussion elaborate on the main barriers and enablers for urban planning to incorporate a transition perspective when tackling urban sustainability challenges. Four main fields of tension emerge as particularly relevant: 1) Democratic representation versus involvement of forerunner innovators, 2) Formal decision-making procedures versus reflexivity and social learning, 3) Standardised project formats versus open processes of searching and experimentation, and 4) Fragmented policy agendas and budget lines versus integrated and multi-sectoral interventions.

The case study illustrates how urban planning struggles to align its rationale with requirements for managing complex sustainability transformations. The findings point to a paradox inherent in planning for transformation: although urban planning necessarily incorporates the values and rules of the currently dominant urban systems, it also has the potential to create windows of opportunity for niche innovations to emerge at district or even city level. Therefore, urban planning processes form an arena in which conflicts between niches and regimes are negotiated.
\end{abstract}

Keywords: Urban sustainability transitions, Urban transformations, Urban planning, Transition management

\section{Science highlights}

- Transformative planning focuses on actors' agency, disruptive initiatives, reflexivity and social learning

(c) The Author(s). 2020 Open Access This article is licensed under a Creative Commons Attribution 4.0 International License, which permits use, sharing, adaptation, distribution and reproduction in any medium or format, as long as you give appropriate credit to the original author(s) and the source, provide a link to the Creative Commons licence, and indicate if changes were made. The images or other third party material in this article are included in the article's Creative Commons licence, unless indicated otherwise in a credit line to the material. If material is not included in the article's Creative Commons licence and your intended use is not permitted by statutory regulation or exceeds the permitted use, you will need to obtain permission directly from the copyright holder. To view a copy of this licence, visit http://creativecommons.org/licenses/by/4.0/ 
- Urban planning is an arena of confrontation between transformative practices and orthodox regime performance

- Transformative initiatives activated through democratically inclusive urban planning depend on actors' power relations and their strategies to increase agency

- Administrative procedures may compromise the reflexivity and social learning elements of planning for transformation

- Revisiting the conception of project's quality criteria become crucial to enable searching and experimentation processes through urban planning. Transformative planning requires holistic and integrated approaches anchored to specific urban management instruments

- Urban planning is both a barrier to and an enabler of transformative change

\section{Policy and practice recommendations}

- Make the governance of planning processes open and inclusive to enable effective transformation

- Adapt administrative procedures to open and exploratory methodologies

- Incorporate intangible results such as reflexivity and social learning as criteria of projects' quality

- Develop specific management instruments to address holistic and integrated approaches

\section{Background}

Sustainable urban transformation has been used to emphasise the structural dynamics of transformation processes involving radical and multi-dimensional change to reorient urban development towards sustainability (McCormick et al. 2013). In this sense, sustainable urban transformation would encompass "both sustainable urban structures and environments and (radical) economic, social, cultural, organizational, governmental and physical change processes" (Ernst et al. 2016, p. 2988). In close relationship with the idea of sustainability transitions, the notion emerges as a response to persistent problems confronted by contemporary societies and entails radical transformation processes that are interconnected and interdependent, but which take place in different domains (Grin et al. 2010). A transition can be conceived, then, as a spiral that reinforces itself with multiple causalities and co-evolution (Rotmans et al. 2001).

Transition scholars have emphasised the relevance of various elements to understand the complexity of transition processes in urban contexts. First of all, the transition management approach focuses on shaping a new governance framework to articulate the influence of actors on advancing transitions (Frantzeskaki et al. 2018a). Despite its name, it assumes that managing or controlling sustainability transitions is not possible, due to the complex and systemic interdependencies amongst problems as well as between urban actors. On the contrary, transitions are seen as a matter of involving multiple actors and aligning them around common long-term goals by incorporating the transition vision into their own operating context and concrete interventions (Loorbach 2007). Transition management aims to influence systemic change through the creation of protected spaces for actors to explore and build alternatives, as well as to challenge the status quo through experimentation and learning. In enabling the innovation of urban actors, increasing their visibility, and anchoring them in the urban context while 
supporting strategic alignment, the mediation of knowledge and creation of opportunities for developing initiatives become crucial for transition management approaches (Hölscher et al. 2018). Furthermore, the socio-technical systems transition approach emphasises the tension between emerging niches and stabilised regimes as being the specific conflictive dynamic that has the potential to bring about sustainable change. From this institutional perspective, socio-technical regimes are understood as a set of stabilised rules that not only provide guidance and orientation to the activities of the different stakeholders, but also ensure their coordination and the dynamic stability of the socio-technical configuration. While regimes are embedded within a landscape, niches are the locations where radical innovation takes place (Geels 2004, 2011). From this perspective, an urban transition would imply fundamental changes in multiple regimes' cultures, structures, and practices as a consequence of the tensions between regime rules and the landscape, the stress of internal mismatches in the functioning of the regimes, and the pressure of alternative options developed by niche agents (Frantzeskaki and de Haan 2009). The important role of power relations and actors' agency in tackling such tensions is widely recognised (Frantzeskaki et al. 2018a). Consequently, urban transformation processes are assumed to involve fundamental changes in the ways of doing (practices), the ways of thinking (cultures), and the ways of organising (structures) (Ehnert et al. 2018a, 2018b).

To introduce sustainability transitions' thinking into urban contexts, Frantzeskaki et al. (2018b), p. 77 emphasise the relevance of strategic urban planning processes and the patterns of empowerment, mobilisation and activation they create. The crucial question is, however, whether these patterns actually enable change agents to contribute to transformation processes, or if urban planning remains a set of institutionalised practices that articulate the cultures, structures, and practices of the current regimes and, thus, tend to resist radical change (Wolfram 2018, p. 119).

Taking the above elements into account, the purpose of this paper is to explore the extent to which urban planning can, in practice, incorporate urban transitions management, while at the same time hinder some of its key elements. We address this concern in a specific empirical context-the city of Valencia in Spain-through a qualitative case study focusing on the ISUD Strategy process for the El Cabanyal district during the period 2015-2018. Our aim is to identify the main barriers and drivers for urban planning to incorporate a transition perspective, and to discuss the potentials and limitations of urban planning to embrace transformation processes that enable sustainability transitions. Consequently, two interrelated questions are addressed in this paper: 1) What are the barriers and limitations for urban planning to incorporate transformative approaches? And 2) What are the drivers and potentials for urban planning to open up and steer towards sustainable urban development pathways?

The paper is structured as follows. First, a theoretical framework is presented in order to conceptualise the relationship between urban planning and transition approaches. Second, the research approach and methodology are explained, detailing how the empirical work has been carried out and explaining the specific position of the researchers in relation to the planning process analysed. Third, the selected case study of the ISUD Strategy in Valencia is presented and discussed in terms of its transformative ambitions in targeting a traditional mixed-use urban area facing multiple issues of social, economic, and environmental degradation. Fourth, the main fields of tension between 
urban planning and transition management that have been identified through the research process are discussed. These revolve around four essential conflict types: 1) Democratic representation versus involvement of forerunner innovators, 2) Formal decision-making procedures versus reflexivity and social learning, 3) Standardised project formats versus open processes of searching and experimentation, and 4) Fragmented policy agendas and budget lines versus integrated and multi-sectoral interventions. Finally, conclusions are drawn on how to transform urban planning so that it becomes an enabling arena for maximising the potential of transformative urban agents.

\section{Theoretical framework: incorporating transition management perspectives into urban planning}

A convergence between urban planning and transition management is problematic in as far as some of their constitutive elements remain clearly incompatible. Urban planning has evolved from a rationalist approach, in which scientific-technical knowledge was assumed to be the key element to master the irrationalities of society and achieve political neutrality through technical competence and objectivity, to a diversity of practices that embrace a variety of rationalities (Wolfram 2018). Throughout this evolution, urban planning has progressively incorporated elements that resonate with transition management thinking (ibid.). Incrementalism has addressed urban planning from a pragmatic perspective which is focused on action and the practical implementations than can be achieved through 'mutual adjustment' and consensus. In this view, emphasis is placed on connecting ends with present conditions, trial and error, learning to test policies, continuous adaptation, and a concern for plurality (Allmendinger 2017) that resemble some key elements of transition thinking. Analogously, participatory and advocacy planning have considered planning to be a space for the exercise of citizenship and democracy (Arnstein 1969), where diversity, dialogue, and power relations are assumed to be crucial. This clearly resonates with the broad deliberations and legitimacy required for sustainability transitions. In addition, collaborative planning drew on Habermas's communicative rationality to assume that knowledge is socially constructed, reasoning can take a great diversity of forms and people's interests are shaped in specific social contexts (Healey 1997). Therefore, planning is conceived as a communicative process whose democratic quality depends on the conditions of deliberation. This preoccupation for how knowledge is collectively built and how social learning is enabled establishes a clear link with transition thinking. Finally, strategic planning highlighted concerns for driving the dynamics of urban development (Ander-Egg 1991) with an emphasis on creating visions, acknowledging external conditions, differentiating strategic and tactical actions, generating alliances, and enabling learning and adaptation, all of which correspond to transition management thinking.

However, various fundamental differences remain. While urban planning is deeply institutionalised and has been globally incorporated into public administration practices, transition management still largely remains in the realm of certain academic and policy networks, but has scarcely been applied in cities. Rather than becoming integrated with the mainstreaming governance modes, transition management aims to add a complementary "meta-governance layer guided by (cross-boundary) systems thinking” (Wolfram 2018, p. 121). This does not necessarily fit with the existing institutions of urban planning since it disputes some of their constitutive assumptions and requires a "free space" for 
developing transformative innovation processes. Thus, there are four key characteristics in terms of embeddedness, intent, and content (Wolfram 2018) that need to be considered in order to understand how transition management perspectives can be incorporated into urban planning practices to enable its transformative potential (see Table 1).

The first element to consider is the explicitly normative orientation of transition management approaches in comparison to urban planning (Wolfram 2018). In particular, the transformative intent of transition management has been clearly stated by focusing on sustainability transformations (Wittmayer et al. 2018) and systemic change processes (Frantzeskaki et al. 2018b) that encompass radical and multi-dimensional innovations to reorient urban development towards sustainability (McCormick et al. 2013), involving (radical) economic, social, cultural, organisational, governmental, and physical shifts (Ernst et al. 2016). Although urban planning is also normative, especially when related to sustainable development (Meadowcroft, 1997), its connection to deep societal transformation processes is not only less articulated, but also contradictory. In fact, urban planning strongly supports the currently existing regimes and thereby tends to resist radical change (Wolfram 2018). For this reason, enabling the transformative potential of urban planning through the incorporation of transition management

Table 1 Analytical categories of the research

\begin{tabular}{|c|c|}
\hline ANALYTICAL CATEGORIES & Key contents \\
\hline Normativity & $\begin{array}{l}\text { - Radical transformation processes that are interconnected and } \\
\text { interdependent but take place in different domains (Grin et al. 2010) } \\
\text { - Radical and multi-dimensional change to reorient urban development to- } \\
\text { wards sustainability (McCormick et al. 2013) } \\
\text { - (Radical) economic, social, cultural, organisational, governmental and } \\
\text { physical change processes (Ernst et al. 2016) } \\
\text { - Fundamental changes in the ways of doing (practices), the ways of } \\
\text { thinking (cultures) and the ways of organising (structures) (Ehnert et al. } \\
\text { 2018a, 2018b) } \\
\text { - Focuses on transformative change (Wittmayer et al. 2018) } \\
\text { - Systemic change processes (Frantzeskaki et al. 2018b) }\end{array}$ \\
\hline $\begin{array}{l}\text { Participation and co-production } \\
\text { of knowledge }\end{array}$ & $\begin{array}{l}\text { - Role of power relations and actors' agency (Avelino and Wittmayer 2016; } \\
\text { Frantzeskaki et al. 2018a) } \\
\text { - Facilitates co-creation processes to provide pathways to visionary futures } \\
\text { (Wittmayer et al. 2018) } \\
\text { - Role and initiative of civil society (Wolfram 2018; Walsh 2018) } \\
\text { - The role of frontrunner actors and of regime incumbent actors } \\
\text { (Frantzeskaki et al. 2018b) } \\
\text { - Patterns of empowerment, mobilisation, and activation created by strategic } \\
\text { urban planning processes for change agents to put their innovative potential } \\
\text { for transformations in such processes (Frantzeskaki et al. 2018b) }\end{array}$ \\
\hline $\begin{array}{l}\text { Innovation and disruptive } \\
\text { initiatives }\end{array}$ & $\begin{array}{l}\text { - Development and diffusion of radical alternatives (Loorbach et al. 2015) } \\
\text { - Relevance of niche activity (Walsh 2018) } \\
\text { - Incorporation of transformative innovation (Walsh 2018) } \\
\text { - Creation of protected spaces for interactive design, experimentation and } \\
\text { learning (Walsh 2018) } \\
\text { - Enabling innovation of urban actors, increasing their visibility and } \\
\text { anchoring them (Hölscher et al. 2018) } \\
\text { - Embed innovations in structures, practices, and discourses (Hölscher et al. } \\
\text { 2019) }\end{array}$ \\
\hline Reflexivity and social learning & $\begin{array}{l}\text { - Incorporate a reflexive stance (Walsh 2018) } \\
\text { - Open processes of searching and experimentation. Position } \\
\text { experimentation at the core of reflexive practices (Wittmayer et al. 2018) } \\
\text { - Challenge the status quo through experimentation and learning (Hölscher } \\
\text { et al. 2018) } \\
\text { - Exploratory approach. Processes of learning from, replicating, and upscaling } \\
\text { experiments (Ehnert et al. 2018a, 2018b) }\end{array}$ \\
\hline
\end{tabular}


perspectives implies acknowledging fundamental normative orientations and ways of thinking (cultures) (Ehnert et al. 2018a, 2018b).

The second element that connects urban planning and transition management is participation and co-production of knowledge. Urban planning concerns for democratic legitimacy (Arnstein 1969; Healey 1997) have generated a great multiplicity of formal and informal procedures for public consultation and citizen participation at city and district level. Therefore, a significant number of methodologies and techniques have been developed in order to articulate open and inclusive governance processes around urban planning. Additionally, the advancement of transdisciplinarity and the incorporation of a strategic and integrated stance into planning (Ander-Egg 1991) have shaped the proliferation of additional procedures to address cross-boundary issues between territories, sectors, and levels (Wolfram 2018). Also in transition management, facilitating co-creation processes to provide pathways to visionary futures (Wittmayer et al. 2018) and co-creation of knowledge are essential (Frantzeskaki et al. 2018a, 2018b). Additionally, power relations and actors' agency and participation in transition processes are receiving a growing amount of recognition (Frantzeskaki et al. 2018a; Avelino and Wittmayer 2016). Particular attention has been placed on the involvement of frontrunners that face a specific issue and advance processes of change through social and technological innovation. For transition management, the driving role and initiative of civil society is therefore far more crucial than in urban planning (Walsh 2018; Wolfram 2018). Conversely, the role of regime incumbent actors is often perceived as resisting transformative change. This is, however, not always the case as "the role of changeinclined regime actors in connecting niche innovations with existing structures and processes is acknowledged as critical to gain support and legitimacy" (Frantzeskaki et al. 2018b, p. 74). In their study of the role of actors in supporting or opposing transitions, Fischer and Newig (2016) identify that actors' roles can change over the course of time. A certain analogy emerges between participatory urban planning and transition management in terms of the crucial concern for the "patterns of empowerment, mobilisation and activation they create [...] and how change agents can put their innovative potential for transformations in such processes" (Frantzeskaki et al. 2018b).

The third element to consider in the integration of transition thinking into urban planning processes is the role of innovation and disruptive initiatives. According to Walsh (2018), transition-oriented urban planning requires the explicit consideration of the relevance of the activity of niches in the emergence of new solutions, as well as the recognition of transition management not only as a governance framework, but also as an action guideline and specific heuristic to incorporate such transformative innovation into urban planning processes. Consequently, niche management and the creation of protected spaces for interactive design, experimentation and learning become crucial for the incorporation of disruptive innovations that address transition challenges. Although strategic planning in the field of sustainable development has incorporated the idea of demonstration projects as a way of enabling learning and advancing collective endeavours (Loeckx et al. 2004), for transition management the development and diffusion of radical alternatives is crucial (Loorbach et al. 2015). Transformative urban planning would require not only enabling the innovation of urban actors and increasing their visibility, but also embedding these innovations into structures, practices, and discourses (Hölscher et al. 2019). 
The transformative potential of transition management relies on the ability to challenge the status quo through experimentation and learning (Hölscher et al. 2018). Consequently, reflexivity and social learning are the fourth element that a transition-oriented urban planning should acknowledge. In this sense, urbanism is expected to incorporate a reflexive stance (Walsh 2018) in which experimentation is placed at the core of planning practices (Wittmayer et al. 2018) to enable processes of learning from, replicating, and upscaling innovations (Ehnert et al. 2018a, 2018b). Considering that transition management "is less about managing and more about influencing transitions through the creation of spaces for searching, learning, and experimenting" (Wittmayer et al. 2018, p. 81), a transition-oriented urban planning would need to incorporate an exploratory approach in which learning from innovative practices also enables institutional change. This idea clearly resonates with the essential idea of communicative planning to not only democratise knowledge production in urban planning, but also enable processes of social learning and critical reflexivity that will be able to affect values, practices, and institutions. At the same time, the transition management idea to link long-term-visions to medium and short-term actions and position experimentation at the core of reflexive practices clearly corresponds to the strategic planning principles (Ander-Egg 1991; Albrechts 2004) of developing a collective long-term vision, deriving and implementing short-term projects and trials, and organising learning processes for continuous adaptation. Urban planning theory has acknowledged the need to incorporate open processes of searching and experimentation that are equally crucial for transition management (Wolfram 2018).

\section{Research methodology}

The analysis has been conducted on the basis of an interpretative research paradigm (Miles et al. 2014; Corbetta 2007) in which qualitative methods have been combined to comprehend and understand the different viewpoints of the diverse actors involved in the issue at hand. This interpretative stance assumes that the centre of each social phenomenon, as well as the activity of the social researcher, is occupied by individual action endowed with meaning. Thus, comprehending social action implies focusing on the understanding of the meanings that individuals construct about their reality and the sense they give to their actions (Vallés, 1997).

Under this view, it is not only necessary to distinguish what is being observed and analysed, but also from which perspective it is being considered. This leads us to recognise our research perspective as being necessarily biased, in the sense that we approach our object from a certain point of view, which is not the only one possible, as it only makes sense in relation to the issues we are addressing. It is also a critical perspective as we do not simply accept explanations that seem to be plausible at first instance, but assume that reality lends itself to different readings, aiming to compare and contrast them all in order to explicitly address contradictions and conflicts (Estruch 2003).

The research methodology is based on the analysis of a critical case study (Flyvbjerg 2011) as a way of developing a deep empirical investigation of one specific phenomenon in order to understand its configuration and reach broader conclusions through the elaboration of theoretical explanations (Venesson 2013). The specific interest of our case study rests on its potential to illustrate the possibilities and limitations of an urban planning process to incorporate transition management practices in a particular setting. This allows us to contribute to a wider debate on how urban planning 
may or may not advance toward transformative approaches. The research design combines a deductive approach in which theory is used as a framework to observe reality through analytical categories defined by the theoretical framework. These categories are crucial for the research objective because they enable us to formulate hypotheses and distil empirical findings that explain to what extent the planning process analysed is oriented towards sustainability transitions.

The role of the researcher is relevant and must be explained as it conditions the entire process of observation, analysis, and interpretation. In this study, one of the researchers had an important role in the development of the case study, being the councillor of the City Council of Valencia politically responsible for the design and implementation of the ISUD Strategy for El Cabanyal during the period from June 2015 to July 2017. During this time, insights were gained from within the process through direct and continuous interaction with the different actors involved that provided a deep understanding of their particular visions, interpretations, and motivations. According to Valles (1997), this kind of direct observation can be categorised as full participant observation. Afterwards, as a university researcher without responsibilities in the local government, the researcher made a conscious decision to distance himself from his previous role, in order to adopt a critical and reflective analytical position, as well as to put personal biases into perspective through systematisation and triangulation of the available information.

Various kinds of data were collected for the analysis. Desk research was performed in order to review relevant documentation of the process, including: 1) the key officially approved ISUD Strategy documents ${ }^{1}$; 2) research, media, and articles on El Cabanyal and the rehabilitation process; and 3) video recordings of particularly relevant events in the formulation of the strategy. ${ }^{2}$ Additionally, semi-structured interviews were conducted with different stakeholders of the process in order to address and contrast the different elements of our framework. The interviewees included members of the local administration $(n=3)$, professional and technical staff involved in the process $(n=3)$, and people from civic organisations, platforms, NGOs and community-based organisations $(n=6)$. Concerning the latter category of actors, the social map elaborated during the formulation of the strategy ${ }^{3}$ was used to identify key actors representing different discursive positions that coexist in the process, mainly those related to: 1) associations and platforms of residents, merchants, and professionals actively involved in the defence of the district; 2) cultural initiatives with a social base in the neighbourhood; and 3) social organisations working with vulnerable groups.

All the data collected was analysed according to the categories of the theoretical framework. Coding was carried out through a combination of descriptive, in vivo,

\footnotetext{
${ }^{1}$ The analysed documents are: 1) EDUSI Cabanyal_Canyamelar_Cap de França, 2) EDUSI Procedures manual, 3) EDUSI Implementation Plan, 4) EDUSI Creation of the Light Intermediate Organism, 5) 13 Minutes of Meeting of the Light Intermediate Organism from 01/03/2017 to 26/04/2018, 6) 35 officially approved description sheets of EDUSI operations.

${ }^{2}$ The analysed video recordings are: 1 ) Third workshop of the strategy formulation process on selection and prioritisation of operations, $13 / 11 / 2015 ; 2$ ) Presentation of the strategy at El Cabanyal, 22/12/2015; 3)

Approval of the strategy at the City Council plenary, 23/12/2015.

${ }^{3}$ The social map can be consulted at:http://www.valencia.es/edusi3c/sites/default/files/docs/e.d.u.s.i._cabanyalcanyamelar-cap_franca_compressed.pdf
} 
process, and evaluation coding (Miles et al. 2014). The information was subsequently reorganised in a matrix to display potentials and barriers for each of the main conceptual categories of the research. The analysis of this information allowed four main fields of tension to be identified as the characteristics of the case study. The categories of the analytical matrix were used to flesh out the interpretation and understanding of these four tensions. The discussion section of the paper has been structured accordingly. All steps were iterative rather than linear as insights gained in the initial analysis were progressively complemented and contrasted in the following steps that nurtured both the analysis and the interpretation of the case.

\section{The integrated sustainable urban development (ISUD) strategy Urban place in transition: El Cabanyal}

The district of El Cabanyal ${ }^{4}$ is a complex place whose current delimitation corresponds to the old municipality of Poble Nou de la Mar, ${ }^{5}$ which was annexed by Valencia in 1897. At present, it is one of the most singular urban settings in the city of Valencia due to its urban layout, its traditional low-rise constructions, its cultural heritage, and its architectural and urban design. It was originally a district with a strong maritime identity and its own traditions, characterised by civic vitality and the diversity of its population.

\section{Historical perspective in regime-niche tensions}

The origins of El Cabanyal go back to the thirteenth century, when a group of fishermen and their families settled settled on the coast. Over time, the fishermen's village grew and at the beginning of the nineteenth century it was established as the municipality of Poble Nou de la Mar, with its own autonomy and council.

At the beginning of the twentieth century, Poble Nou de la Mar became increasingly dependent on Valencia, although its spatial configuration, morpho-typological rules, and inhabitants' lifestyles were clearly distinct from those of the city. On one hand, its city council was incorporated into the municipality of Valencia; on the other, it was physically absorbed by the growth of Valencia towards the sea. This urban expansion was structured by Blasco Ibáñez Avenue, which connected the city with El Cabanyal (Varea et al. 2016; Navarro 2014).

In 1979, with the advent of democracy in Spain, the socialist government gave recognition to the singularity of the neighbourhood by protecting some areas through specific planning laws. Several district areas became Protected Heritage Spaces in 1988, and the entire district was declared a place of cultural interest by the Valencian Government in 1993.

However, with the election success of the conservative People's Party, ${ }^{6}$ a Special Plan for the Protection and Internal Reform of El Cabanyal (PEPRI) was approved in 1998, which included the extension of the Blasco Ibáñez Avenue right through the core of the neighbourhood, the demolition of 1651 houses, and the construction of new residential buildings (Varea et al. 2016; Navarro 2014). Urban planning, thus, essentially

\footnotetext{
${ }^{4}$ The term "El Cabanyal" is used here to refer to the district of El Cabañal-Canyamelar-Cap de França in the city of Valencia.

${ }^{5}$ Place name, which means: New Town by the Sea.

${ }^{6}$ The People's Party (Partido Popular) is a conservative party integrated in the European People's Party.
} 
became a technocratic tool for advancing political goals aligned with the construction and real-estate industries.

PEPRI was immediately contested by the movement "Salvem El Cabanyal" (Let's save El Cabanyal), a newly created platform composed of neighbourhood, civic, cultural, and traders' associations. The platform mobilised directly affected inhabitants as well as broader sectors of the city including professionals, activists, opposition political parties, cultural and educative groups, and individual citizens. They developed a large range of imaginative community-based activities to raise public awareness of the traditional, cultural, architectural, heritage, and social value of the district. These activities included, for instance, opening up the houses to the public, creating a living graphic archive of the district, or making artistic performances. ${ }^{7}$

In this way, the City Council and Salvem El Cabanyal became opposing poles for confrontations between supporters and opponents of the expansion of the Avenue, highlighting the potential of local social movements to challenge administration plans (Varea et al. 2016). Thus, for seventeen years, Salvem El Cabanyal became a niche of social activism through a flurry of innovative cultural initiatives-some of which received strategic support from European institutions ${ }^{8}$ - technical activities, and cocreation of transdisciplinary knowledge with professionals and universities. This allowed it to expand its room for manoeuvre and public recognition, and also facilitated legal actions in court that managed to paralyse the implementation of the urban plan (PEPRI). This long-lasting civic resistance provided El Cabanyal with widespread visibility at the local, national, and European levels.

However, during this period, the district suffered continuous urban aggressions by regime actors and deliberate degradation in an attempt to promote and legitimise the expansion of the avenue through physical destruction, social degradation, and disintegration. Some of the houses were demolished or became abandoned, inhabitants were subjected to pressure to sell their homes, and a new socially excluded population settled in. In addition, a growing lack of quality in public services increased the sensation of it being an abandoned neighbourhood. All these elements initiated a gentrification process in which urban poverty and social exclusion were expected to finally legitimise the massive urbanistic intervention while concealing its essentially speculative motives (Varea et al. 2016, Salvem El Cabanyal, 2015).

\section{A change in the local government}

In February 2015, prior to the local electoral campaign held in May, Salvem El Cabanyal issued a statement requesting public commitment to address the problem. They called for "a democratic debate involving all the actors concerned, especially those who have less capacity to make their voices heard" (Salvem, El Cabanyal 2015, p. 3) and defined some general criteria for action including sustainability, participation, local economy, public facilities, urban regeneration, and social cohesion. Specifically, they demanded the elaboration of a participatory strategy in order to address an integrated rehabilitation of El Cabanyal. All political parties in the opposition signed this petition and publicly supported its contents.

\footnotetext{
Some of the initiatives were Cabanyal Portes Obertes, Cabanyal Arxiu Viu, and Craft-Cabanyal.

${ }^{8}$ El Cabanyal Archivo Vivo, a project aimed at raising awareness of the value of the maritime districts of Valencia, received the European Union Prize for Cultural Heritage in 2013.
} 
Thereby, the issue of El Cabanyal gained considerable momentum to the point of becoming one of the main themes of the local electoral campaign. After the elections, a new municipal government emerged from an agreement between three left-wing political parties, ${ }^{9}$ thus reverting the situation and making the rehabilitation of El Cabanyal a public policy priority. One of the first political measures of the new municipal government was to derogate the PEPRI and establish transitory urban regulations for the period during which a new Special Urban Plan for El Cabanyal ${ }^{10}$ (PEC) was to be elaborated.

\section{A strategy aimed at transforming the district}

In July 2015, the new city council began to deploy a set of policy initiatives for a holistic regeneration and revitalisation of the district through the combination of various financing instruments. In first place, it launched the Integrated Sustainable Urban Development Strategy (ISUD Strategy) to attend the open call ${ }^{11}$ of the Ministry of Finance and Public Administrations to allocate European Regional Development Funds (ERDF). It consisted of a planning process for district regeneration that was explicitly focused on enabling transformation towards sustainable development. In agreement with the call, four thematic priorities were included: 1) Information and communications technologies; 2) low carbon economy transition; 3) urban environment and heritage; and 4) social inclusion, poverty, and discrimination. The strategy commanded around 30 million euros of public investment, including the EU co-funding, through a holistic programme of 13 lines of action and 52 operational programmes that were officially approved in December 2015 by the City Council. Second, the establishment of an Urban Regeneration and Rehabilitation Area (ARRU) mobilised around an additional 13 million euros, mainly devoted to housing rehabilitation, one of the key issues after fifteen years of physical degradation. Third, the Special Plan of Support for Productive Investment in Municipalities (PIP) involved somewhere in the region of 23 million euros more for urbanisation and the modernisation of streets and water infrastructure. Finally, the European Social Fund was also incorporated with around a further one million euros for training and employment programmes (EDUSI 2015).

Within this policy framework, involving an overall investment of around 67 million euros for El Cabanyal, the role of the ISUD Strategy was crucial as its participatory processes provided content not only to the lines of action of the strategy itself, but also to the other three complementary regeneration and funding instruments (ARRU, PIP, and the European Social Fund). A fundamental characteristic of the ISUD Strategy is that it was conceived as an innovation project. In fact, it was promoted by the Councillor of Innovation and, due to its integrated and interdisciplinary nature, it was the Innovation Service that became responsible for the overall management within the municipality. Likewise, the development of the strategy was articulated, supported, and coordinated through "Las Naves", the Valencia City Council centre for urban innovation. Las Naves is a public entity that depends on the City of Valencia and promotes urban innovation

\footnotetext{
${ }^{9}$ Compromís, Partit Socialista del País Valencià, and València en Comú.

${ }^{10} \mathrm{PEC}$ is the urban planning instrument that defines land use and heritage management.

${ }^{11}$ This call was part of the the Europe 2020 Strategy for the growth and employment of the European

Commission and was organised through the Network of Urban Initiatives (RIU) within the framework of the

Operational Programme for Sustainable Growth (OPSC) 2014-2020. The RIU is the main national

coordination mechanism for urban development and European community.
} 
with a focus on people's well-being. It has a multidisciplinary team that works in different areas such as urban mobility, energy, health, and agro-food, and promotes innovation through direct involvement and participation of members from public administration, private sectors, academic and research institutions, and civil society. This innovation-based perspective shaped the whole strategy formulation process as well as its contents.

\section{A participatory process}

The regulatory framework of the European urban policy 2014-2020 (ERDF) asks for citizen participation during both the formulation and the implementation phases. This idea was clearly aligned with the district's longstanding appeal to qualify rehabilitation with citizen participation. Consequently, these top-down and bottom-up demands for participation mutually reinforced one another in settling a participatory process for the elaboration of the strategy.

The ISUD Strategy formulation was driven by an external team of interdisciplinary professionals under the umbrella of a project named Va Cabanyal!. ${ }^{12}$ They developed a methodology in which the technical work was developed in parallel to a participatory process designed to enable collaborative and reflective action amongst the multiple social agents. ${ }^{13}$ The aim was to develop a strategy which responded to people's aspirations. In this sense, one of the key innovations of the ISUD Strategy was the involvement of citizens in a bottom-up progression in which the main contents of the strategy emerged from the deliberative spaces opened up by the planning process. Although the open participatory process was an initiative driven by the City Council, the involvement of the municipal services followed the definition of different proposals in the public spaces of participation and targeted their refinement.

One of the main challenges of the Va Cabanyal! methodology was to redistribute decision-making power among social agents to reach a consensus and to build a holistic and shared vision of the desired neighbourhood. The integration of interdisciplinary knowledge was crucial and various working groups ${ }^{14}$ were created to this end during the formulation process. Several participatory spaces were opened up in a process that was carried out in three stages: 1) analysis and co-diagnosis by addressing all the dimensions of the ERDF call and grouping them into five areas ${ }^{15}$ to make them more accessible to participants, 2) generation of proposals, and 3) definition and prioritisation of lines of action and operations. A social map was developed, and multiple interviews and sectorial meetings were held with a large part of the actors, as well as participatory workshops of mass attendance at the end of each stage. Furthermore, various communication channels ${ }^{16}$ with citizens were opened, both digital and face-to-face, and specific activities for young people's participation were set up through "Va Cabanyal for Kids". The resulting lines of action were structured according to the thematic priorities

\footnotetext{
${ }^{12}$ The team was composed of architects, citizen participation technicians, urban planners, sociologists, psychologists, environmentalists, and specialised consultants in research, development, and innovation.

${ }^{13}$ The overall collaborative formulation of the strategy was carried out in around 5 months.

${ }^{14}$ Coordination Technical and Process Management Group, Driving Group, Communication and Broadcasting Group, Technical-Administration Group.

151) Public space and housing, 2) Economy and employment, 3) Environment, 4) Living together, and 5) Governance

${ }^{16} \mathrm{An}$ office in the neighbourhood, a suggestion box, a web page, twitter, email, and a questionnaire.
} 
of the ERDF call and the proposals were transformed into operations. A final workshop was held in order to present the overall ISUD Strategy and discuss its contents with the different actors and citizens.

Concerning the implementation phase, some guidelines were established for the type of required participation where citizens, social organisations, and public administration should work together, in a multi-level governance system.

\section{An integrated and cross-cutting strategy}

The scope of the ISUD Strategy covers very diverse areas of urban development derived from a comprehensive understanding of its social, cultural, economic, environmental, and physical aspects. The collaborative formulation led to an integral and cross-cutting programme that addressed the multiple layers that shape the complexity of the district, going well beyond its physical dimension. In this way, 13 lines of action emerged, and 52 operations were defined to be implemented by 15 municipal services working through transversal coordination. The lines of action defined through the participatory process were adapted to the thematic priorities defined by the ERDF: 1) universal access to ICT; 2) sustainable urban mobility; 3) energy efficiency; 4) cultural heritage; 5) urban environment; 6) physical, economic, and social regeneration; 7) housing; 8) cultural programmes; 9) employability and socio-occupational integration; 10) commercial reactivation; 11) comprehensive support for vulnerable families; 12) management and control of the programme; 13) governance, partnership, and coordination (EDUSI 2017). According to the professionals involved in the process, the four thematic priorities were both broad and flexible enough to accommodate all the lines of action that had been defined and prioritised through the participatory process.

\section{Multi-level governance organisation}

The participatory, integrated, and transversal nature of the ISUD Strategy, meant implementation required the definition of a multi-level governance system to establish the relationships between stakeholders and embed the guidelines of the ERDF into the overall organisation of the programme.

The ERDF established that the Ministry of Finance and Public Administration was responsible for the strategy and for ensuring that implemented actions corresponded to the established guidelines. In this sense, the ministry became an intermediary body while municipalities were the executing agency. According to the management procedures, a Light Intermediate Organism (LIO) was created within the municipality to undertake supervisory responsibilities. It was an administrative body in charge of monitoring the implementation of the strategy, approving operations, and verifying their correct execution. According to the Procedure Manual, the city council services had to design operations in detail and submit an Expression of Interest to the LIO for approval during the implementation phase. Additionally, a Political Monitoring Committee was created. It was chaired by the mayor and composed of councillors to provide the project with the required political support.

The governance system designed for the process included mechanisms for direct interaction with citizens and social actors in El Cabanyal. Its aim was to enable a reflexive monitoring of the process maintaining the "coherence of the strategy from both the 
point of view of municipal and citizenship will, as established in the formulation process" (EDUSI 2017). It included the establishment of a Political-Technical-Citizen Monitoring Committee and other mechanisms for dialogue between the public administration and social actors, as well as a continuous and open evaluation of the process to introduce corrections. In fact, the thirteenth line of action of the strategy was specifically included to provide the governance system with the required resources.

\section{Discussion: underlying fields of tension and controversies}

As explained in the previous section, the ISUD Strategy was explicitly created to enable a sustainable urban transformation at district level in El Cabanyal. However, when analysing the initiative through the application of our analytical categories, our research identifies four main fields of tension, which are discussed in this section.

\section{Democratic inclusion versus innovation in the definition of the strategy}

Transformative approaches to planning acknowledge the crucial role of civil society and the relevance of niches (Walsh 2018). In our case study, the ISUD Strategy draw on different kind of social initiatives developed in the neighbourhood that were aimed to advance novel forms of doing, thinking and organizing. However, despite formal alignment, frictions emerged around underlying normative orientations related to social concerns, civic initiatives, cultural proposals and technological innovations. Power relations and actors intend to increase their agency were crucial to understand how these initiatives were activated through the strategic urban planning process.

The overall design process of the strategy was focused on enabling democratic participation and deepening participatory democratic practices through direct involvement of organisations, groups, and individuals in the definition of the strategy contents. A broad initial emphasis was made on communicating the strategy elaboration process and gaining extensive collaboration of all the relevant actors in the neighbourhood. The overall definition of the strategy contents was built collectively through participatory methodologies in which diversity was addressed by listening to all the relevant voices. Although the regulatory framework of the European programme established a set of four thematic objectives, they were both broad and flexible enough to accommodate the contents defined in the participatory spaces. Differences were addressed through methodologically guided deliberative discussions and consensus-based agreements between participants, reaching a formulation of the strategy which seemed to be widely agreed upon by the different social collectives in the district.

One of the key features of the strategy was its innovative nature, both in the process and in its contents. This was made explicit on several occasions, particularly in the open public presentation held at El Cabanyal where the potential of the experience in terms of learning and replication in other districts of the city was emphasised. Specifically, many of the initiatives in the strategy were considered as disruptive in the context of Valencia as they set up new practices, new ideas, and new forms of organisation, such as: housing rehabilitation through cooperatives, cession of public land for urban "masovería", ${ }^{17}$ the establishment of a Civic Centre to set up social initiatives by district

\footnotetext{
${ }^{17}$ Urban "masovería" is an agreement in which the owner grants the right to live on his or her property without paying rent in exchange for making refurbishments and maintaining the house in good condition.
} 
collectives, ICT-based telecare system for elderly and dependent people, communitybased support programmes for vulnerable families, community urban gardens and sports areas with social integration programmes, or energy efficiency through smart housing and demonstrative buildings. Many of these initiatives aimed to gather and develop the existing projects and concerns of the social organisations of the neighbourhood by reinforcing their role and action in the rehabilitation of the district.

Democratic inclusion seems not to have been at odds with disruptive innovation, but many discrepancies surfaced during the process in terms of normative orientations. According to our research, the strategy contents ware modulated by the different actor's capacity to influence the overall process to advance their own visions and priorities. In this sense, the consensus reached was shaped by the different actor's agency and their relative power of influence in a complex network of relations. The different actors built its power base and legitimacy to influence the process through various strategies including advocacy, social representativeness, technical expertise, and lobbying; but two clear poles of influence emerged in the definition of the strategy. On one side, the actors grouped around the civic platform Salvem el Cabanyal, with a strong representativeness and social mobilisation capacity, that aspired to return to normality after years of physical and social deterioration; and on the other, a group of organisations that had gained relevance through their social tasks with the more vulnerable groups. It is widely recognised that both had a significant influence on the final content of the strategy. In terms of innovative actions, the rehabilitation of the old slaughterhouse to set up a cultural centre for the interpretation of the neighbourhood with an active role from civic associations clearly resonates with the cultural initiatives developed around Salvem el Cabanyal during 17 years of resistance against the former City Council. ${ }^{18}$ Furthermore, the community-based programmes for vulnerable families, or the social and intercultural viewpoints incorporated to urban gardens, sports areas, kindergartens, and training programmes are clearly linked to the influence of the other group of organisations. In any case, neither of these poles of influence seem to be representative for innovation niches in key areas of the strategy, such as energy or housing. However, the process seems to have left the actors, at least at the definition stage, enough room for manoeuvre to include innovative initiatives in these areas. This is particularly the case of those related to communication and information technologies, which responded to the thematic objective of the ERDF call regulatory framework, even though residents did not consider them to be as essentially focused on the urgent needs of the district. This gap was solved by merging the different actors' agendas through the incorporation of specific communication and information technology into other lines of action, such as a programme for universal access to technology and elimination of the digital divide, a spatial network of air pollution sensors, or a programme for awareness-raising, auditing, and monitoring of family energy consumption.

In terms of actors' normative orientations, the process contributed towards establishing the idea that existing discrepancies could be resolved through dialogue and deliberation. Therefore, an emergent pattern resulting from the reflexivity of the actors

\footnotetext{
${ }^{17}$ Urban "masovería" is an agreement in which the owner grants the right to live on his or her property without paying rent in exchange for making refurbishments and maintaining the house in good condition. ${ }^{18}$ In fact, the old slaughterhouse was the place where Salvem el Cabanyal used to hold their assemblies and meetings.
} 
themselves was that a radical and multi-dimensional change to reorient urban development towards sustainability required a cross-cutting incorporation of social and intercultural perspectives into interventions of a diverse nature. However, the articulation of actors' agencies in the district had a difficult connection with the logic of the implementation phase, as will be seen below.

\section{Procedures versus reflexivity and social learning in the implementation of the strategy}

According to our theoretical framework, incorporating transformative approaches into urban planning involves acknowledging the role of regime incumbent actors, not only to increase the visibility of niche actors but also to reinforce their innovative capacity and to embed their innovations into structures and practices (Hölscher et al. 2019). This involves developing exploratory and reflective incremental approaches to enable learning in order to replicate and upscale experiments (Ehnert et al. 2018a, 2018b).

The case study clearly shows how administrative procedures may compromise some of the essential elements of planning for transformation, especially those related to reflexivity and social learning. In the case of Valencia, there are two elements that appear to have been especially determinative. The first is the impasse period between the formulation of the strategy and its official approval. The City Council approved the strategy in December 2015, but it was not until October 2016 that a favourable decision was received from the Ministry of Finance and Public Administration. During these months of uncertainty, the overall strategy was broken down into the specific operations emerging from the participatory process, some of which were transferred to other regional government complementary programmes in order to secure funding. This is how the ISUD Strategy participatory process came to define not only the ERDF funds, but also the overall set of investment instruments used at El Cabanyal. However, people in the neighbourhood felt that time was passing by and projects had not started. Consequently, the articulation of actors' agency for transformative change around the strategy started to resent.

The second element is the complex administrative arrangement within the City Council for the management of the strategy. There is broad consensus on the view that the creation of the LIO and the Procedures Manual-derived from the ERDF regulatory framework management approach-was extraordinarily tedious and confusing due to the added bureaucratic burden, the lack of knowledge of what was required, and unclear guidelines from the Ministry of Finance and Public Administration. Consequently, administrative arrangements added further delays to the initial impasse time from the formulation to the approval of the strategy. Thereby, the LIO was not formed until February 2017, the Procedures Manual was not approved until March 2017, the internal process for the definition of operations was not launched until June 2017, and the first official approval of operations took place at the end of September 2017. That is around 2 years after the participatory process for the definition of the strategy took place; even then, it did not mean that operations would start at that time, only that the different municipal services initiated the process of issuing, drafting, and formulating projects and operations.

Given that some urgent problems of the district remained unsolved during this period (particularly issues related to daily social coexistence, social ghettoisation, and 
drug dealing) the delays in the implementation of operations produced a clear sense of disillusion in the organisations involved in the process. Although most of these operations are recognised to be important in the medium and long term, the invisibility of the administrative and bureaucratic work led to a loss in the initial enthusiasm. The perception that almost nothing had been done was quite common and publicly expressed by the organisations in the district and clearly point to the fact that the timescale for the public administration is quite distant from the timescales and expectations of the people and organisations that are involved in these processes. Consequently, social actors ceased to perceive the strategy as a space to exercise their agency.

It is particularly remarkable how the burden of procedures diverted energy and capacity for developing spaces for dialogue and reflection around the strategy. As previously mentioned, the original formulation of the strategy, through its Implementation Plan, included a specific operation devoted to articulating a governance structure for the coordination of the strategy. All relevant actors from both the municipality and the citizenry were expected to become involved in the design, implementation, consolidation, and reflective monitoring of the strategy. This governance system was conceived as dynamic and was expected to be able to adapt to changing needs through a "continuous and participatory evaluation of the process" (EDUSI 2015). However, it was not officially approved by the LIO until September 2017, and it was not until October 2018 that the operation was assigned, through a public tender, to a specialised team. Almost 3 years after the approval of the strategy, this operation, which was considered as a prerequisite for enabling cross-cutting coherence throughout all the strategy, had still not started due to the burden of administrative procedures. Therefore, the lack of spaces for open communication and dialogue blocked the possibilities for collective social learning in the implementation of the strategy. Although the regulatory framework of the ERDF programme clearly encouraged continuous participation and dialogue during the implementation phase of the strategy, in the case of Valencia a contradiction occurred in the fact that the bureaucratic burden derived from that same framework also hindered it.

The case study clearly shows a clash of rationalities between the initial open dialogue-based reflexivity of the design phase and the subsequent procedural and regulatory rationale of the implementation phase. Transformative approaches assume the relevance of enabling and developing agency of social urban actors in the development of disruptive initiatives that contribute to systemic change. That was the original aim of the ISUD process. However, the connection between novel planning approaches and the orthodoxy of procedures has revealed itself to be deeply problematic.

\section{Standard projects versus open processes of searching and experimentation}

A crucial aspect of transformative urban planning involves creating protected spaces for interactive design and experimentation in order to enable transformative learning processes (Walsh 2018). This implies considering experiments as the core element to enable reflexive practices (Wittmayer et al. 2018) and to adopt a reflexive stance (Walsh 2018). However, when the analysis is extended to the project level, controversies between administrative and transformative rationalities become even more acute in relation to the possibilities of implementing open process of searching and experimentation. In this sense, the 
regime rules clearly manifested themselves through the rationale of public administration projects procedures and, specifically, through the overall administrative apparatus established by the ISUD Strategy management and control guidelines. This rationaladministrative logic works on the assumption that projects must follow a sequential flow that goes from a clear initial definition to their subsequent implementation. This hinders possibilities for more open and iterative processes, which are essential for advancing in the search and experimentation of innovative initiatives. Thereby, projects are expected to be fully defined in advance and the quality of the different proposals has to be mainly assessed according to objective criteria, of which the cost is the most important. This logic was fully embedded in the ISUD Strategy administration system. However, the original innovation-oriented logic encountered serious difficulties in fitting into this logic due to two main issues.

First, it was due to the question of project quality criteria. The ISUD Strategy formulation conceived a type of quality related to the process itself that did not necessarily fit into the objective criteria commonly used in public administration. Intangible results such as reflexivity, experimentation, and learning, or the generation of a community of practice are extremely difficult to incorporate into the current standardised procedures. Particularly, the question of downward tenders in public contracts was often mentioned as an important drawback to quality. The importance given to cost as a selection criterion, and the possibility of operating through a reverse auction, clearly damages intangible elements of project quality such as participation, reflexivity, and social learning. Although it is law that regulates these procedures, innovation and change in the regulation of this kind of public project implementation is perceived as necessary to connect novel planning perspectives with the institutional machinery.

Second, it is a question of participatory and exploratory approaches being essential elements of the ISUD Strategy philosophy. Coherently, during the implementation phase, participation and stakeholder's involvement was considered crucial at an operational level to collectively reflect, define alternatives, and reach agreements from amongst the various feasible options. However, many difficulties arose when it came to fitting these ideas into administration procedures, even though ISUD Strategy included specific budget lines for them. Consequently, no spaces for collective design and co-creation of specific projects were created. The Civic Centre is a paradigmatic example. Due to its social and civic relevance, it was originally expected to be co-designed and co-defined with the overall social fabric organisation of the district. However, due to the urgencies derived from the initial delays and the administrative procedures that had to be followed, the Civic Centre was designed in a professional manner through a public call for tenders. This combination of highly rigid procedures and the need to initiate projects clearly damaged the capacity to create a collective endeavour amongst public administration and social actors and, thus, harmed the possibilities of articulating the agency of the diverse urban actors in the district.

To some extent, administrative rationality seems to have prevailed in the operative definition of the projects. When the planning processes started at El Cabanyal, there was a flurry of social initiatives that the strategy aimed to reinforce through the development and embedding of social innovation, but it faced the barrier of rigidly standardised legal-regulative procedures. Initiatives that were expected to be developed in a participatory, cross-cutting, and collaborative manner were being developed through 
dynamics that do not really fit into this philosophy due to the rigid nature of institutional procedures. Consequently, some of the most disruptive initiatives included in the initial formulation were transformed into more standardised projects. The required flexibility and adaptability of transformative emergent processes that were defined in the initial strategy formulation came up against the capacity of the existing management resources and administrative instruments of the ISUD Strategy.

\section{Fragmented policy agendas and budget lines versus integrated and multi-sectoral interventions}

Transformative approaches acknowledge the interconnection and interdependence of change processes that take place in different domains (economic, social, cultural, organisational, governmental, physical, etc.) (Grin et al. 2010). Therefore, transferring the urban transition focus on transformative change (Wittmayer et al. 2018) to urban planning approaches necessarily involves incorporating a systemic change perspective (Frantzeskaki et al. 2018b) into their operating ways.

In our case study, the strategy as a whole was multisectoral but the ability of the existing instruments to manage this systemic approach found some difficulties. In tune with the systemic perspective of the ISUD Strategy, many of the innovative transition projects it included also required an integrative perspective and the involvement of various areas of competence in the City Council for their development. In fact, a relevant component in terms of disruption and transformation was the cross-cutting integration of certain elements of diversity and interculturality in diverse types of interventions. Nevertheless, the fragmented nature of the public administration structure represented a serious challenge.

One of the key aspects was the disaggregation of the whole programme into the different budget lines of the City Council. These budget lines consisted of the basic management units for the different services of the municipality which are clearly specialised in their areas of competence. The problem appeared when a specific project required the integration of diverse competences, in which case the budget had to be divided into budget lines and managed independently. This was the case of the School-Workshop for socio-occupational integration. One of the key requirements was to adapt it to the particularities of the neighbourhood. To this end, the teaching and management of the training programme was assigned to the Employment and Entrepreneurship Service, which had the tools and instruments to carry them out, while the conceptualisation and design was assigned to the Social Welfare and Integration Service, which had the specific knowledge to define the formative profiles according to neighbourhood needs. Although its success has not yet been proven, this kind of arrangement was replicated in some other projects in the programme. The ISUD Strategy has shown how integrated interventions are a clear pattern of novel transformative planning approaches, but it being anchored to the city council management system proved to be a difficulty, due to the lack of specific management instruments to implement projects in a more integrated way amongst different municipal services.

Our case study also evidences that, however important management instruments may be, integrated and cross-sectoral interventions are also a matter of political coherence. Considering the integrative and holistic component of transition projects, it has been 
suggested that dysfunctionalities derive from the very existence of councils themselves. Particularly, the existence of different political agendas has been pointed out as an element that may have challenged the overall cohesion of the strategy (Varea et al. 2016). In our case study, the challenge of political coherence was particularly relevant due to the fact that the local government was made up of three different parties with different ideological slants, who governed in coalition. For that reason, the existence of a Political Monitoring Committee where political differences could be addressed through dialogue in the search for agreements and consensus was crucial. This evidenced how the political realm of transformative planning approaches needs to incorporate a spirit of compromise and cooperation in the articulation of the different municipal areas of responsibility.

\section{Conclusion: the planning for transformation paradox}

This paper has explored how the incorporation of transition management perspectives into urban planning has the potential of advancing conceptual and practical foundations for a transformative planning approach. To this end, a theoretical stance has been adopted in which transition-oriented urban planning is assumed to be based on four key elements. First, a normative approach in which transitions are linked to disruptive and systemic multi-dimensional change. Second, participation and co-production of knowledge through transdisciplinary approaches and inclusive governance to empower change agents and enable their transformative potential. Third, acknowledgment of the crucial role of innovation, experimentation and disruptive initiatives developed in niche spaces and the processes to embed them into structures, practices, and discourses. And fourth, the deliberate creation of reflexivity and social learning spaces to enable institutional change.

Through the analysis of an integrated strategy planning process in the city of Valencia, we have seen how these emerging patterns have been incorporated into the initial stages of the process and how their interaction with the orthodoxy of statutory planning was particularly relevant in the impasse between the design and the implementation phase. At this stage, a clash of rationales and mental models took place in which transformative planning conceptions confronted the formal technical-procedural slant of the administration. Although, the strategy was led by the innovation area of the local government, the original participatory, innovative, and reflexive approach which impregnated the conception of the different actions had a difficult translation into the administrative processes to be undertaken by the different municipal services in the implementation of the projects.

Consequently, some lessons can be derived in relation to the four identified tension fields that urban planning faces in the incorporation of transition management perspectives. In first place, the activation of innovation through democratically inclusive urban planning requires an open and inclusive governance of the process that enable transformative actors to enhance their agency. The need for intermediaries directly working with the civil society organisations in the field, reinforcing their innovative potential and connecting them to the institutional machinery is crucial to keep dialogue spaces open for collective discussions, interactions, and social learning. Therefore, the initial design phase of strategy planning must result in the governance system being prepared and opend up. This not only requires the 
mobilisation of specific resources, but also their ready availability, since it is a prerequisite to transversally incorporate a transformational perspective to the rest of operations. Second, administrative procedures may compromise the reflexivity and social learning elements of planning for transformation. Consequently, revisiting the formal criteria of project quality is essential to incorporate a transformative perspective. Intangible results such as reflexivity, experimentation, and social learning are extremely difficult to incorporate into the current standardised procedures. However, the required flexibility and adaptability of emergent transformative processes needs to be part of the existing management and administrative instruments. Third, exploratory approaches and methodologies need to be incorporated into current project administration procedures to develop open processes of searching and experimentation. Although it is law that regulates these procedures, innovation and change in the conceptual models underpinning the regulation of public project implementation is needed in order to connect novel planning perspectives with administrative mechanisms. Finally, the tensions identified between the fragmentation of policies and budget lines and the need for multi-sectoral interventions highlight the relevance of holistic and integrated approaches as a clear pattern of novel transformative planning approaches. From a technical perspective, being anchored to the organisational system requires the development of specific management instruments to implement projects in a more integrated manner. From a political perspective, transformative planning approaches need to incorporate a spirit of compromise and cooperation in the articulation of the different municipal areas of responsibility.

As an overall conclusion, we identify the existence of a planning for transformation paradox. Even though urban planning necessarily incorporates the values and rules of currently dominant urban systems due to its submission to standardized procedures and regulations, it also has the potential to create windows of opportunity for niche innovations to emerge at a district or even city level. Therefore, urban planning processes appear as an arena where confrontation between transformative and orthodox practices takes place. This has important implications for urban planning. In order to address urban sustainability transformations, planning needs to effectively incorporate innovations in terms of its conceptualisation, governance, processes, methodology, and organisation in order to give transformative practices a chance to emerge and diffuse. Although grounded in a single case study with a specific background, these results may be relevant for other contexts to enable comparative research and dialogue between experiences.

As a site of contestation, the ISUD Strategy in Valencia is an ongoing story, the ending of which is still to be written. Various future pathways are open, but all the ground covered so far has provided invaluable lessons. Nevetheless, a transition to sustainability has only just started in the district. Consequently, future research would be required in order to address the analysis of the tangible and intangible results of the strategy and the evolution of the four tension fields. Particularly promising would be to analyse the role of this kind of strategies in terms of their contributions to increase the overall transformative capacity of a district by adopting the urban transformative capacity framework (Wolfram 2016). It would imply to enlarge some of the discussion lines developed in this article but also to 
incorporate new ones. The focus could then be placed on understanding the extent to which such strategies enable the emergence of new forms of inclusive governance, modulate and reinforce transformative leadership and consolidate communities of practices for district-based innovation; as well as on discussing the development of methodologies and tools for systemic urban transition management and the qualification of public administrative procedures for incorporating innovation-oriented approaches.

\section{Abbreviations}

ARRU: Urban Regeneration and Rehabilitation Area; ERDF: European Regional Development Funds; ISUD: Integrated Sustainable Urban Development Strategy; LIO: Light Intermediate Organism; OPSC: Operational Programme for Sustainable Growth; PEPRI: Special Plan for the Protection and Internal Reform of El Cabanyal; PIP: Special Plan of Support for Productive Investment in Municipalities; RIU: Network of Urban Initiatives

\section{Acknowledgements}

We want to acknowledge all the interviewees for their participation and also the reviewers of the journal and the editors of the special issue for their valuable contributions.

\section{Authors' contributions}

Each author has made substantial contributions to the conception and design of the work; the acquisition, analysis and interpretation of data; has drafted the work and substantively revised it and they have approved the submitted version. Each of them agrees both to be personally accountable for the author's own contributions and to ensure that questions related to the accuracy or integrity of any part of the work, even ones in which the author was not personally involved, are appropriately investigated, resolved, and the resolution documented in the literature.

\section{Funding}

The research was carried out without specific funding.

\section{Availability of data and materials}

Materials described in the manuscript, including all relevant raw data, will be freely available to any scientist wishing to use them for non-commercial purposes, without breaching participant confidentiality. The datasets used and/or analysed during the current study are available from the corresponding author on reasonable request.

\section{Ethics approval and consent to participate}

No ethics approval is required. All the interviewees have consented to participate.

\section{Consent for publication}

Not applicable.

\section{Competing interests}

The authors declare that they have no competing interests.

\section{Author details}

${ }^{1}$ Universitat Politècnica de València, València, Spain. ${ }^{2}$ Universitat Politècnica de València, València, Spain.

Received: 9 April 2019 Accepted: 22 May 2020

Published online: 08 July 2020

\section{References}

Albrechts L. Strategic (spatial) planning reexamined. Environ Plann B. 2004;31:743-58

Allmendinger P. Planning theory. 3rd ed: London: Palgrave Macmillan; 2017.

Ander-Egg E. Introduccion a la Planificación. Siglo XXI; 1991.

Arnstein S. A ladder of citizen participation. JAIP. 1969;35:216-24.

Avelino F, Wittmayer JM. Shifting power relations in sustainability transitions: a multi-actor perspective. J Environ Pol Plan. 2016;18:628-49.

Corbetta P. Metodología y técnicas de investigación social. Madrid: McGraw-Hill; 2007.

EDUSI. Estrategia De Desarrollo Urbano Sostenible Integrado Para El Cabanyal - Canyamelar - cap De França. València: Ajuntament de València City; 2015.

EDUSI. Plà d'implementació; 2017.

Ehnert F, Frantzeskaki N, Barnes J, Borgström S, Gorissen L, Kern F, et al. The acceleration of urban sustainability transitions: a comparison of Brighton, Budapest, Dresden, Genk, and Stockholm. Sustainability. 2018b;10(3):612. https://doi.org/10.3390/ su10030612.

Ehnert F, Kern F, Borgström S, Gorissen L, Maschmeyer S, Egermann M. Urban sustainability transitions in a context of multilevel governance: a comparison of four European states. Environ Innov Soc Trans. 2018a;26:101-16. https://doi.org/10. 1016/j.eist.2017.05.002.

Ernst L, De Graaf-Van Dinthera RE, Peek GJ, Loorbach DA. Sustainable urban transformation and sustainability transitions; conceptual framework and case study. J Clean Prod. 2016;112:2988-99. 
Estruch J. La perspectiva sociológica. In: Cardús S, editor. La mirada del sociólogo. Barcelona: Qué es, qué hace, qué dice la sociología: Universitat Oberta de Catalunya; 2003.

Fischer LB, Newig J. Importance of actors and agency in sustainability transitions: a systematic exploration of the literature. Sustainability. 2016;8:476. https://doi.org/10.3390/su8050476.

Flyvbjerg, B. Case study. In: Denzin MK, Lincolns YS. Sage Handbook Of Qualitative Research. 4th Edition. Thousand Oaks: SAGE Publishing; 2011

Frantzeskaki N, Bach M, Hölscher K, Avelino F. Introducing sustainability transitions' thinking in urban contexts. In: Frantzeskaki N, Hölscher K, Bach M, Avelino F, editors. Co-creating sustainable urban futures, vol. 11. Future City: Springer; 2018b.

Frantzeskaki N, Bach M, Mguni P. Understanding the urban context and its challenges. In: Frantzeskaki N, Hölscher K, Bach M, Avelino F, editors. Co-creating sustainable urban futures, vol. 11. Future City: Springer; 2018a.

Frantzeskaki N, de Haan H. Transitions: two steps from theory to policy. Futures. 2009;41:593-606.

Geels FW. From sectoral systems of innovation to socio-technical systems: insights about dynamics and change from sociology and institutional theory. Res Policy. 2004;33:897-920.

Geels FW. The multi-level perspective on sustainability transitions: responses to seven criticisms. Environ Innov Soc Trans. 2011;1:24-40

Grin J, Rotmans J, Schot J. Transitions to sustainable development, new directions in the study of long term transformative change. New York: Routledge; 2010.

Healey P. Collaborative planning: shaping places in fragmented societies. 2nd ed. Basingstoke: Palgrave Macmillan; 1997.

Hölscher K, Frantzeskaki N, McPhearson T, Loorbach D. Capacities for urban transformations governance and the case of new York City. Cities. 2019;94:186-99.

Hölscher K, Wittmayer JM, Loorbach D. Transition versus transformation: What's the difference? Environ Innov Soc Trans. 2018; 27:1-3.

Loeckx A, Shannon K, Tuts R, Verschure H. Urban Trialogues, Visions_projects_co-productions. Localising agenda 21. Leuven: UN-HABITAT and PGCHS K.U; 2004.

Loorbach D. Transition management: new mode of governance for sustainable development. Utrecht: International Books; 2007.

Loorbach D, Frantzeskaki N, Huffenreuter LR. Transition management: taking stock from governance experimentation. J Corp Citizsh. 2015;58:48-66.

Meadowcroft, J. Planning, democracy and the challenge of sustainable development. International Political Science Review. 1997;18(2):167-189. https://doi.org/10.1177/019251297018002004

McCormick K, Anderberg S, Coenen L, Neij L. Advancing sustainable urban transformation. J Clean Prod. 2013;50:1-11.

Miles M, Huberman M, Saldaña J. Qualitative data analysis. Thousand Oaks: SAGE Publishing; 2014.

Navarro L. Salvem el Cabanyal: urban movements and their claim for the "right to the City". VLC arquitectura. Res J. 2014;1: 47-61.

Rotmans J, Kemp R, Asselt M. More evolution than revolution: transition management in public policy. J Futur Stud Strateg Think Policy. 2001;3:15-32.

Salvem El Cabanyal. Manifiesto Febrero 2015. 2015.

Valles MS. Técnicas cualitativas de investigación social. Síntesis: Reflexión metodológica y práctica profesional; 1997.

Varea A, Bascuñana P, Català L, Caparrós P, Azorín F. Construir la ciudad colectivamente. De la exclusión social al bien común. In: Lluch E, Bono E, Baeza N, editors. Medio Ambiente y Política social. Análisis y Perspectivas Comunitat Valenciana, 2016; 2016. Observatorio de Investigación sobre Pobreza y Exclusión en la Comunitat Valenciana.

Venesson, P. Estudios de casos y seguimiento de procesos. In: Della Porta, D., Keating, M. (coord.). Enfoques y metodologías de las ciencias sociales. Una perspectiva pluralista. Akal City: Madrid; 2013.

Walsh P. Translating transitions thinking and transition management into the City planning world. In: Frantzeskaki N, Hölscher K, Bach M, Avelino F, editors. Co-creating sustainable urban futures, vol. 11. Future City: Springer; 2018.

Wittmayer JM, Van Steenbergen F, Frantzeskaki N, Bach M. Transition management: quiding principles and applications. In: Frantzeskaki N, Hölscher N, Bach M, Avelino F, editors. Co-creating sustainable urban futures. Cham: Springer; 2018.

Wolfram M. Conceptualizing urban transformative capacity: a framework for research and policy. Cities. 2016;51:121-30

Wolfram M. Urban planning and transition management: rationalities, instruments and dialectics. In: Frantzeskaki N, Hölscher K, Bach M, Avelino F, editors. Co-creating sustainable urban futures, vol. 11. Future City: Springer; 2018.

Publisher's Note

Springer Nature remains neutral with regard to jurisdictional claims in published maps and institutional affiliations.

Ready to submit your research? Choose BMC and benefit from:

- fast, convenient online submission

- thorough peer review by experienced researchers in your field

- rapid publication on acceptance

- support for research data, including large and complex data types

- gold Open Access which fosters wider collaboration and increased citations

- maximum visibility for your research: over $100 \mathrm{M}$ website views per year

At $\mathrm{BMC}$, research is always in progress.

Learn more biomedcentral.com/submissions 